\title{
Profile of Women Seeking To Know Fetal Sex at Ultrasoun in a Nigerian Obstetric Population
}

\author{
Ngwan S.D ${ }^{1}$., Mohammad H²., Edem B. $E^{3}$., Hwande T.S ${ }^{4}$., Eke B ${ }^{5}$., \\ Obekpa A.S . $^{6}$ \\ ${ }^{1 \& 4}$ Department of Obstetrics \& Gynaecology, Federal Medical Centre, Makurdi \\ ${ }^{2}$ Department of Radiology, Benue State University Teaching Hospital, Makurdi \\ ${ }^{3}$ Department of Anaesthesia, Federal Medical Centre, Makurdi \\ ${ }^{5}$ Department of General Surgery, Benue State University Teaching Hospital, Makurdi \\ ${ }^{6}$ Department of Internal Medicine, Benue State University Teaching Hospital, Makurdi
}

\begin{abstract}
:
Background/Objectives: It Is Possible That Not All Women Would Want The Disclosure Of Fetal Sex Or Gender By The Sonologist During An Antenatal Or Perinatal Scan.

The Objective Of This Study Was To Determine The Proportion Of Women That Wanted To Know Fetal Sex At Ultrasound, Group Them And Document Their Reasons For Wanting To Know.

Methodology: This Was Descriptive Study Of Pregnanat Women Who Presented At Our Facility For Antenatal Ultrasound Diagnosis In Makurdi From June 1st To December 31st 2013.

Results: One Hundred And Eighty (180) Women Were Studied Within This Period. Most Of The Women (55\%) Were Of The Tiv Ethnic Group. Ibo And Idoma Women Accounted For 15\% And 13.3\% Respectively. Majority Of The Women Were Christians (93.3\%). Ninety Six Percent (96\%) Of The Women Consent To Disclosure Of Fetal Gender, While Four Percent (4\%) Decline. The Main Reason For Wanting To Know Fetal Gender Was So That They Will Know What To Buy Before Delivery.

Conclusion: Most Of The Women (96\%) Would Want Fetal Gender Disclosure At Prenatal Ultrasound Scan. Only 4\% Of The Women Did Not Want Fetal Gender Disclosure Because They Were Satisfied With Anyone. It Is Therefore Advisable For Any Sonologist To Be Careful On Fetal Gender Disclosure To Pregnant Women During The Procedure, So As Not To Hurt Those That Do Not Want.
\end{abstract}

Key Words: Fetal Sex, Prenatal Ultrasound Scan, Disclosure

\section{Introduction}

It is possible to determine the sex of the fetus transabdominally from 14 weeks of gestation ${ }^{1,2}$. But it is frequently difficult to make a definitive diagnosis until several weeks later. This is usually with the 3D imaging techniques ${ }^{1}$. With the real time ultrasound, fetal sex could be determine from the 16th week of gestation with increasing sensitivity of $97 \%^{3}$ after 20 or more weeks of gestation.

The diagnosis of fetal gender depends upon the fetus having its legs apart and on recognizing the echo patterns characteristics of the male and female respectively. The male srotum and penis can be identified. The test can be visualized in the third trimester.

The accuracy of fetal gender identification on ultrasound may be affected by the amount of liquor present, the number of foetuses, the quality of the machine and the experience of the sinologist ${ }^{3,4}$.

Identifying fetal gender is important in women who are carriers of sex - linked conditions such as haemophilia. In this condition only the male fetus is affected. Other reasons for sex determination are mostly social reasons, which include pressure from family members or husband, wears to buy or personal reasons ${ }^{5,8}$.

Parents seem to be divided as to whether they wish to know the sex of their fetus. It may also be associated with negative or positive effect on the parents. In some countries, there have been restrictive laws on antenatal fetal sex determination because of the fear of parents undergoing termination of an unwanted sex ${ }^{6,10}$. In countries like India, where the population is very high and the law permits only one child, there may be increase incidence of selective abortion and fetocide of an unwanted sex ${ }^{12}$.

In Nigeria, because of the increasing level of education, not every woman may want antenatal ultrasound fetal sex determination before delivery. It is therefore advisable that in any giving country, it would be necessary for the scanner to know how to interpret results to parents. Asking the parents seems to put them under pressure to make a decision one way or the other and many parents assume that if you have asked the question the fetus must be a male ${ }^{6,13}$. Never guess; if you are unsure, say you do not know.

Many studies have shown different reasons why women want fetal gender disclosure ${ }^{3,6,8,14}$, but such have not been carried out in our facility. 
The main objective of this study was to determine the proportion of women that wanted, to know fetal sex disclosure during antenatal ultrasound scan and also document their reasons.

\section{Materials and Methods}

This was a descriptive cross-sectional study carried out at a private radiological diagnostic centre in Makurdi, Benue State, North Central Nigeria. The centre offers ultrasound services with a large turn over for obstetric clients drawn from Makurdi metropolis and its environs, with some from other local government areas. There are two qualified consultant sinologist of comparible competence at the centre.

Consecutive pregnant women who were $\geq 20$ weeks were recruited during the study period. These women were refered for prenatal scan by health care givers or from surrounding hospitals for either a routine scan or specific obstetrics indications. Some pregnant women may come on their own for routine scan. During the study period, each woman that fullfill the inclusion criteria was asked by the sinologist during the scanning if she want to know the sex of the fetus by saying Yes or No. Those that wanted to know had their results disclosed and their reasons documented. Those that decline had their wishes upheld and their reasons also documented.

The ultrasound scan was performed with Kaixin KX $2000 \mathrm{G}$ fitted with a $35 \mathrm{MHz}$ curvilinear transducer. Fetal gender was identified by the sonologic appearace of the external genitalia at the perineum. The male fetus was identified by the presence of the scrotal sac as around echogenic structure separated by an echogenic median raphe and the phallus as an echogenic cylindrical structure (figure 1). The female fetus was recognized by the two labial folds, which showed as two oblong echogenic structures separated by an echo-free area (figure 2).

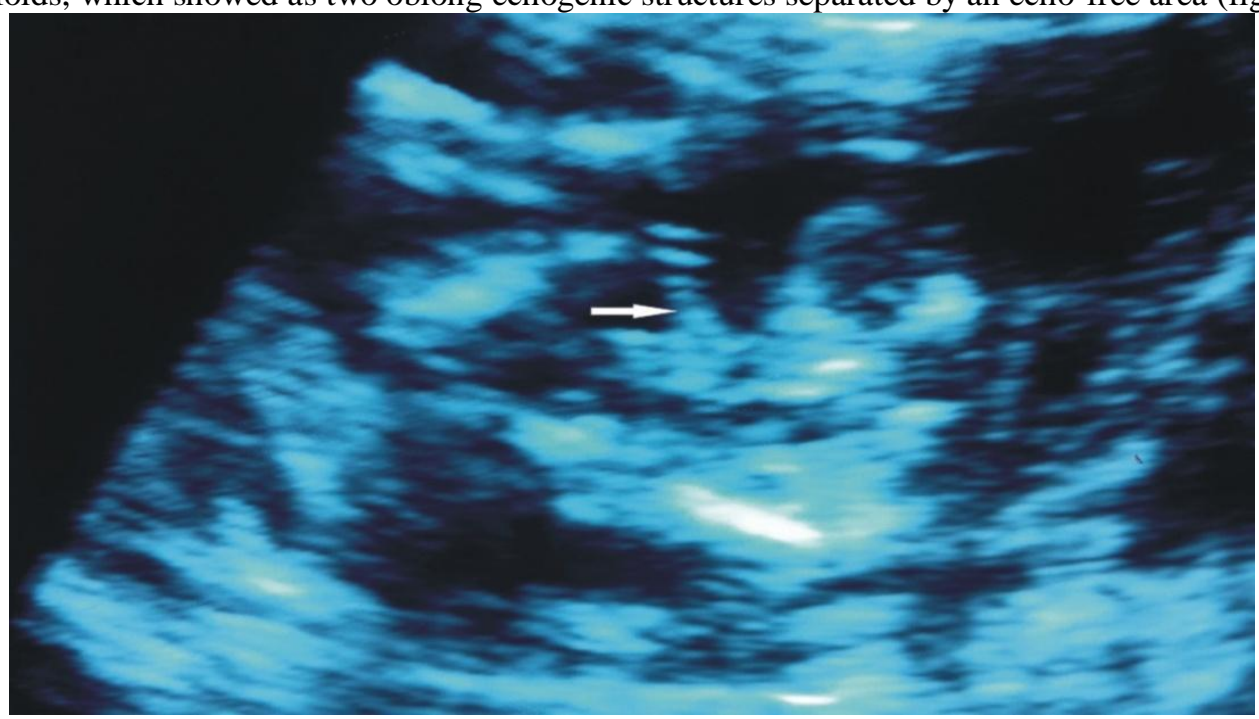

Figure 1

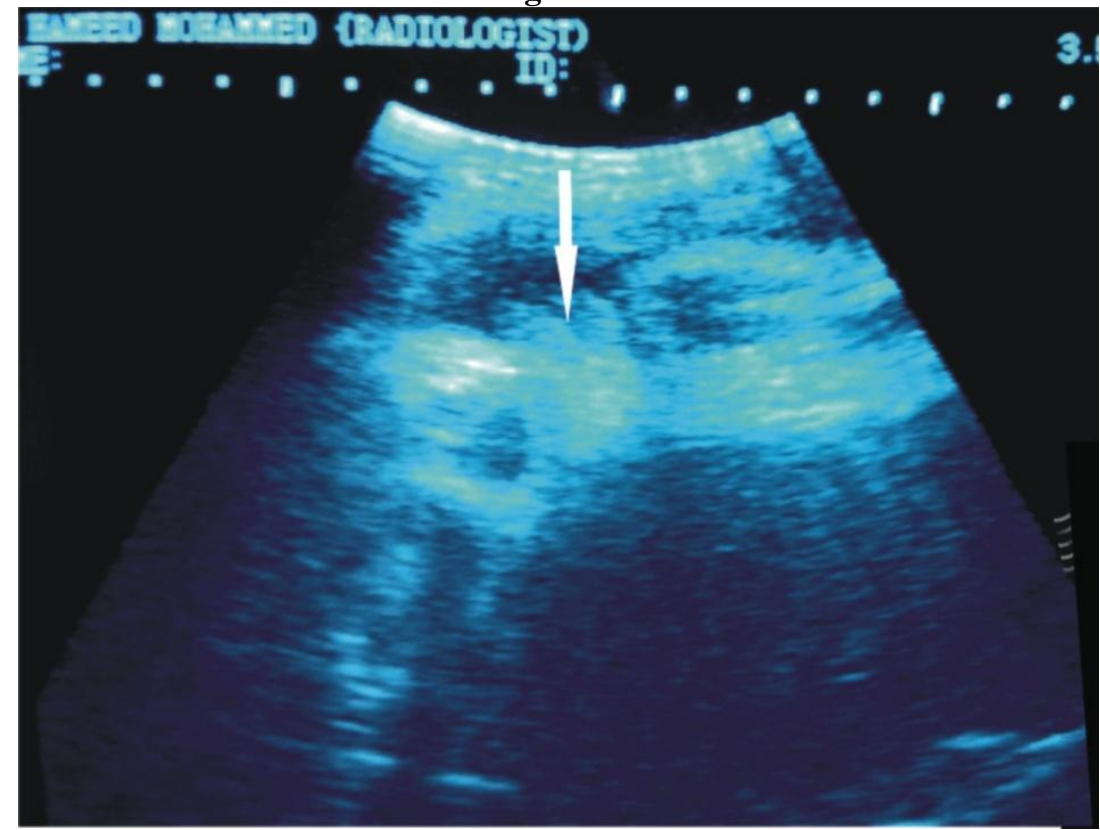

Figure 2 
Information obtained from the women included their age, ethnic group, religion, educational level etc and indication for the scan. The information obtained was entered into Statistical Package for Social science 16.0 (SPSS) software for analysis.

III. Results;

\begin{tabular}{|c|c|c|c|}
\hline Variable & & Frequency & Percentage \\
\hline \multicolumn{4}{|l|}{ Tribe } \\
\hline & Tiv & 99 & 55.0 \\
\hline & Idoma & 24 & 13.3 \\
\hline & Igbo & 27 & 15.0 \\
\hline & Igede & 8 & 4.5 \\
\hline & Yoruba & 4 & 2.2 \\
\hline & Hausa & 9 & 5.0 \\
\hline & others & 9 & 5.0 \\
\hline & Total & 180 & 100 \\
\hline \multicolumn{4}{|l|}{ Religion } \\
\hline & Christianity & 168 & 93.3 \\
\hline & Islam & 12 & 6.7 \\
\hline & Total & 180 & 100 \\
\hline \multicolumn{4}{|c|}{ Educational status } \\
\hline & None & 12 & 6.7 \\
\hline & Primary & 20 & 11.1 \\
\hline & Secondary & 89 & 49.4 \\
\hline & Tertiary & 59 & 32.8 \\
\hline & Total & 180 & 100 \\
\hline \multicolumn{4}{|c|}{ Occupation } \\
\hline & Civil servants & 55 & 30.5 \\
\hline & House wives & 104 & 57.8 \\
\hline & Students & 21 & 11.7 \\
\hline & Total & 180 & 100 \\
\hline \multicolumn{4}{|l|}{ Gravidity } \\
\hline & Primigravidae & 31 & 17.2 \\
\hline & Multigravidae & 149 & 82.8 \\
\hline & Total & 180 & 100 \\
\hline \multicolumn{4}{|l|}{ Age } \\
\hline & $\leq 14$ & 5 & 2.8 \\
\hline & $\overline{15}-24$ & 42 & 23.3 \\
\hline & $25-34$ & 84 & 46.7 \\
\hline & $35-44$ & 30 & 16.7 \\
\hline & $\geq 45$ & 19 & 10.5 \\
\hline & $\overline{\text { Total }}$ & 180 & 100 \\
\hline \multicolumn{4}{|c|}{ Fetal gender disclosure } \\
\hline & Yes & 172 & 96 \\
\hline & No & 8 & 4 \\
\hline & Total & 180 & 100 \\
\hline
\end{tabular}

Table 2: Reasons for wanting to know fetal gender disclosure

\begin{tabular}{lll}
\hline Reasons for wanting to know (172 women) & Frequency & Percentage \\
\hline Know wears to buy & 98 & 57.0 \\
\hline Personal reasons & 30 & 17.4 \\
From husband & 22 & 12.8 \\
Pressure from family members & 20 & 11.6 \\
Sex linked medical disorder & 2 & 1.2 \\
\hline Total & 172 & 100 \\
\hline Reasons for not wanting to know (8 women) & & \\
Personal reasons & 1 & \\
Satisfied with God's choice & 1 & \\
Do not want to know & 1 & \\
Satisfy with anyone & 2 & \\
Have both sexes already & 1 & \\
Prefer to know after delivery & 2 & \\
\hline
\end{tabular}

\section{Discussion}

From the study, most of the women were of the tiv tribe because this is the dominant tribe within the study area, accounting for about 55\%. At least over $80 \%$ of them had secondary school education and therefore likely to request the sinologist to know fetal gender.

Majority of women (96\%) wanted to know fetal sex at prenatal ultrasound in this study. This value is compatible with the study done by Ekele etal in northern Nigeria that showed $95 \%{ }^{1}$ and the Boston study but its 
higher than the $15 \%$ from the same community earlier carried out by the same authors ${ }^{2}$. The main reason for wanting to know fetal gender was so that they will know what clothes to buy for the baby, accounting for $57 \%$. Other reasons for wanting to know fetal sex were either for personal reasons, pressure from husband or family members and sex linked medical disorder. The reasons for such a high percentage (95\%) wanting to know fetal sex is probably due to the fact that about $82 \%$ of the women were literate in the study group and therefore likely to inquire from the sinologist. This is opposite to the study carried out in Sokoto by Ekele etal in which most of their women were not literate.

It is also possible that some women agreed to know fetal sex just to test the accuracy of the findings.

Several other studies in Nigeria have documented lower percentage because the women were given questionnaires to answer Yes or No about knowing fetal sex but if the direct methodology of asking them was applied at the time of the procedure as done in this study, it might have been higher. It means that in matters of this nature, there might be a difference between attitude and the real practice.

Only $4 \%$ of women did not want to know fetal sex but their wishes were respected. This brings to the fact that the habit of running unsolicited commentary during routine antenatal scan, especially if it includes fetal sex, may inevitably hurt the feelings of some of the women. Because of the small number of women (8) that did not want fetal sex disclosure, it was difficult to characterise them statistically. The commonest reason for not wanting to know was - prefers to know after delivery and satisfied with anyone. Other reasons were; do not want to know; satisfied with God's choice, personal reasons and already have both sexes. These reasons were similar to the Shipp et al study ${ }^{8}$.

It therefore remains that should the sinologist wait to be asked by the woman or directly asked by the woman or directly asked the woman if she is interested in fetal sex. So as to know who to tell or not? Some authorities may not subscribe to the proactive approach since it is of little or no clinical significance. Other critics have gone ahead to argue that to routinely ask women might potentially create gender - seeking obstetric ultrasound population which will create pressure on the facility unnecessarily. We therefore recommend that for those that wants to know, it should be disclosed to them or it should be written on their obstetric reports if seen, especially with increasing literacy level of women in most cities.

In conclusion, $96 \%$ of the women in this study wanted to know fetal sex at antenatal ultrasonography when asked by the sinologist. Their reason being that so that they will know what to buy before delivery. Only a smaller percentage of women did not want fetal sex disclosure.

\section{References}

[1]. Grandjean H., Larroque D., Levis 1999. The performance of routine ultrasonographic screening of pregnancies in th eurofetus study. American Journal of Obst Gynaecol 181: 446 - 454.

[2]. Ekele B. A., Maaji S. M., Bello S. O., Morhason-Bello I. O. Profile of women seeking fetal gender at ultrasound in a Nigerian Obstetric population. Ultrasound 2008; 16: $199-202$.

[3]. Okonta P. I., Okobenin S. A., Adeoye - Sunday I. Pregnant Nigerian woman's view of her prenatal sex determination. Jobstet Gynaecol 2004; 24: $875-877$.

[4]. Harrington K., Armstrong V, Freeman J, aquillina J, Campbell S. Fetal sexing by ultrasound in the second trimester: maternal preference and professional ability. Ultrasound obstet Gynaecol 1996; 8: $293-4$.

[5]. Nzeh D. A., Ultrasound determination of fetal gender; Accuracy and Social implications. East Afr med J 1996; $73: 225$ - 7.

[6]. Adekanle D. A., Bello T. O., Odu O. O. Predictors of request for antenatal sex determination among pregnant women in Osogbo, Nigeria. Niger j med 2007; 16: $322-5$

[7]. S. M. Maaji, B. A. Ekele, S. O. Bello, I. O. Morhason - Bello. Do women want disclosure of fetal gender during prenatal ultrasound scan? Annals of Africa Medicine vol. 9, No 1; 2010:11-14.

[8]. Hsiao C. H., Wang H. C., Hsieh C. F., Hsu J. J. Fetal gender screening by ultrasound at 11 to 13 (+6) weeks. Acfa Obstet Gynaecol scand 2008; 87: $8-13$

[9]. Shipp T. D., Shipp D. Z., Bromley B., Sheahan R., Cohen A., Lieberman E., etal. What factors are associated with parents' desire to know the sex of their unborn child? Birth 2004; 31: $272-9$.

[10]. Michailidis G. D., Papageorgiou P., Morris R. W., Economides D. L. The use of three - dimensional ultrasound for fetal gender determination in the first trimester. Br J Radiol 2003; 76: $488-51$.

[11]. Winestine M. C. To know or not to know: Some observations on women's reactions to the availability of prenatal knowledge of their babies' sex. J Am Psychoanal Assoc 1989; 37: 1015 - 30.

[12]. Gu B., Xu Y. A comprehensive discussion of the birth gender ratio in China. Chin J Popul Sci 1994; 6: 417 - 31.

[13]. Kishwa M. When daughters are unwanted: sex determination test in India. Manushi 1995; 86: 15 - 22.

[14]. Sjogren B. Parental attitudes to prenatal information about the sex of the fetus. Acta Obstet Gynaecol Scand 1988; 67: $43-6$.

[15]. The royal college of obstetricians and Gynaecologist: protocol, standards and training. Report of the RCOG working party, July 2000. RCOG, Lodon 